\title{
Effects of Summer Microclimates on Behavior of Lions and Tigers in Zoos
}

\author{
by \\ Tory Young ${ }^{1}$, Esther Finegan ${ }^{2}$, and Robert D. Brown ${ }^{1 *}$ \\ ${ }^{1}$ School of Environmental Design and Rural Development \\ University of Guelph, Guelph, Canada \\ ${ }^{2}$ Department of Animal and Poultry Science \\ University of Guelph, Guelph, Canada \\ *Corresponding Author \\ rbrown@uoguelph.ca \\ phone: $519-824-4120 \times 53619$ \\ fax: 519-767-1686
}

\begin{abstract}
The surrounding thermal environment has a direct influence on the well-being of an animal. However, few studies have investigated the microclimatic conditions that result from outdoor zoo enclosure designs and whether this affects where animals choose to spend time. Two African lions (Panthera leo) and two Siberian/Amur tigers (Panthera tigris altaica) were observed for a total of 18 full days during the summer and fall of 2009. Their activities and locations were recorded to the nearest minute of each test day. Simultaneous on-site microclimate measurements were taken of air temperature, relative humidity, solar radiation, and wind. Observations indicated that the locations where the animals chose to spend time were influenced by the microclimatic conditions. All subjects spent more time in the shade on their sunny warm days than on other days and differed from one another in their choice of shade source on all days. Temperature-comparable sunny and cloudy days showed a greater use of sun on the cloudy days. Speciesspecific differences between the lions (whose native habitat is hot) and the tigers (whose native habitat is temperate with cold winters) were observed with the tigers displaying more cooling behaviors than the lions in terms of solar radiation input and evaporative heat loss. The tigers were also more active than the lions. The results of this study provide new insight into how lions and tigers respond to microclimatic conditions in a captive environment.
\end{abstract}

\section{Keywords}

Thermal comfort, zoo design, enclosure, energy budget, solar radiation

Received: 27 April 2012/Revised: 25 May 2012/Accepted 26 May 2012

NOTICE: This is the authors' version of a work that was accepted for publication in International Journal of Biometeorology. Changes resulting from the publishing process, such as peer review, editing, corrections, structural formatting, and other quality control mechanisms, may not be reflected in this document. Changes may have been made to this work since it was submitted for publication. A definitive version was subsequently published in International Journal of Biometeorology Published online 17 June, 2012 and will be published in print form later in 2012. If you refer to this work please cite the published version. 


\section{Introduction}

Zoo enclosure design strongly influences both the physiological and psychological well-being of captive animals (e.g. Morgan and Tromborg 2007; Webster 1994; Young 2003). Due to the logistics of space and enclosure size, the variety of environmental conditions available to zoo animals is normally greatly reduced from that experienced in the wild, where an animal can choose its preferred ambient environment. The ambient environment that an animal experiences includes the microclimate (thermal experience), tactile experience (e.g. rough/smooth; hard/soft), elevation, acoustics, light intensity, odors, colors, as well as other sensory stimuli. Design of an outdoor enclosure environment may entail selection of vegetation, substrates, surrounding vertical materials, water bodies, topographical elevations and layout and orientation of these features, all of which offer a plethora of options and will have a direct impact on the microclimates available to the animal. If an animal is unable to find a thermally comfortable location through various weather conditions, a consequence is thermal stress, to which prolonged exposure results in a myriad of health concerns.

Temperature has been reported in numerous studies as a behavioral stressor, regarding both individual responses and social interactions (Morgan and Tromborg 2007). Physiologically, heat stress can have deleterious effects on the reproductive cycle during most stages in both males and females (Hansen 2009; Widowski 1998). As the individual animals in zoos are often representatives of their species as part of a breeding program for conservation efforts, ensuring that an enclosure's environment does not unintentionally limit an animal to conditions that are too hot is critical for this species mandate and for the welfare of the individual. Langman et al.'s (1996) study of a sea lion enclosure revealed that, prior to remodeling, the shade area next to the gunite walls was rendered ineffective due to the reflected solar radiation heating the surfaces in the shade to the same temperature as surfaces in sunny areas.

To understand the thermal comfort of an animal, one must understand the interaction between the animal and its environment in terms of heat exchange. An animal's energy budget provides insight into this relationship and is described by the well-known equation (e.g. Brown and Gillespie 1995; Campbell and Norman 1998):

$$
\mathrm{M}+\mathrm{R}_{\mathrm{abs}}=\mathrm{R}_{\mathrm{emit}}+\mathrm{C}+\mathrm{E}+\mathrm{K}+\mathrm{X}
$$


Or: Metabolic heat production $(\mathrm{M})+$ solar and terrestrial radiation absorbed $\left(\mathrm{R}_{\mathrm{abs}}\right)=$ terrestrial radiation emitted $\left(R_{\text {emit }}\right)+$ convective heat loss $(C)+$ evaporative heat loss $(E)+$ conductive heat exchange $(K)+$ storage (X).

The effectiveness of these modes of heat transfer will be affected by the surrounding microclimatic conditions. Of the microclimatic parameters, the effects of solar and terrestrial radiation, wind and precipitation can be modified through the way in which the landscape is designed (Brown and Gillespie 1995); air temperature and humidity cannot.

Many thermal comfort studies have been conducted on agricultural animals, such as cattle, sheep, and pigs, since preventing thermal stress increases productivity, and on laboratory animals, but comparatively, and surprisingly, very few studies have been done for zoo animals (Hosey et al. 2009; Johnson 1997; Kirkwood 1999), many of which evolved for an environment much different than that of the zoo's location. Though the importance of this topic, in relation to an animal's well-being, was addressed by Hediger (1950) over half a century ago, it is only recently being re-identified as an area deserving of further investigation in zoo biology literature (Hosey et al. 2009; Langman et al. 1996; Litchfield et al. 2011). The goal of this study, then, was to investigate the relationship between where zoo animals spend time and the microclimatic conditions in their enclosure in the summer with the hope of leading to better understanding of how to enhance the thermal comfort of zoo animals through design. With an objective to select two species of similar size from the same taxonomic family, with native habitats of climatic extremes from one another and with differing climates from the host zoo, African lions (Panthera leo) and Siberian/Amur tigers (Panthera tigris altaica) were the focus animals of the present study. Being largely uncharted territory, and without the ability to handle zoo animals in the same manner as domesticated animals, this paper is exploratory in nature with a main purpose of forming a foundation for future research.

\section{Materials and Methods}

The study was conducted at the Toronto Zoo in Toronto, Ontario, Canada $\left(43^{\circ} 49^{\prime} 13.00^{\prime \prime} \mathrm{N}\right.$, $79^{\circ} 10^{\prime} 58.00^{\prime \prime}$ ). Four animals were studied: a male and a female African lion and a male and a female Amur tiger. All four animals were captive born. The subjects spent day hours in their outdoor enclosures 
and were housed indoors overnight. Routine meals were given at night, when the animals were brought inside, and in the morning, prior to being let out.

The male lion had an estimated age (as he was a rescue animal) of 15 to 18 years of age and the female lion was 13; each had been at the Toronto Zoo for 15 and 12 years, respectively. The female was a white lion, a natural, but rarely occurring, phenotype that is a distinctly lighter color than the typical lion. The lion enclosure was a $977 \mathrm{~m}^{2}$ outdoor exhibit with varying topography, natural rock, and expansive gunite (artificial concrete rock) surroundings. There were several trees: seven Honey locust (Gleditsia triacanthos), one Ash species (Fraxinus spp.), and an unidentified shrub. There were also three large basking rocks, one real and two gunite.

The male tiger was 16 years old and the female was 13 . The male had been at the zoo since he was just over a year old and the female had been there for 10 years. The tiger exhibit used in this study was $1561 \mathrm{~m}^{2}$ and included a den with mulch floor surrounded by natural rock, a water pool with gunite rock surroundings, varying topography, four English oak (Quercus robur) trees and many trees just outside the enclosure fence.

Ambient temperature $\left({ }^{\circ} \mathrm{C}\right)$ and relative humidity $(\%)$ were measured using a Kestrel 4000 Pocket Weather Tracker (Nielsen-Kellerman, Sylvan Lake, Michigan, USA), solar radiation (W/m²) using an LI250A Light Sensor with an LI-189 Light Meter (LI-COR Biosciences, Lincoln, Nebraska, USA) and wind speed (m/s) using a Sims DIC-3 Anemometer (Simerl Instruments, Annapolis, Maryland, USA). These measurements of microclimate were recorded every 15 minutes of each study day. All of the instruments were mounted immediately outside the animal enclosure for safety reasons. As microclimatic data are all spatially conservative parameters, measurements recorded immediately outside of the enclosures can validly be used to represent the conditions within the enclosures (Brown and Gillespie 1995).

The activity and location of the subject animal were continuously observed and recorded (Martin and Bateson 1993) to the nearest minute beginning between 10:00 and 10:30 a.m. and concluding before sunset, when the animals were let back into their housing for the night hours (between 7:00 and 7:45 p.m. for the first half of the study and at approximately 6:00 for the second half). The two lions were on display at the same time, though only one focus animal was continuously observed each day, and the tigers alternated between the enclosure used in this study and another. All observations were conducted by the 
same person and were carried out from the public viewing areas. With a single observer there was the benefit of gaining a more clear understanding of the subject's disposition throughout the day and over the course of the study than if there had been multiple observers alternating observation periods. Additionally, using a single observer ensured that the methods of observation and recording were consistent.

The activities of felids are not typically affected by the presence of zoo visitors (Margulis et al. 2003), which allowed for the observed behaviors to be isolated from external factors. Periods of time when the animals' behaviors were influenced by the presence of a keeper, such as during the daily keeper talk (when a treat was often given), were omitted from analysis. As well, time periods when the animal was in an area of the enclosure where its activity was not visible to the observer were excluded from analysis. When visual contact with the subject was broken for more than one minute, such as when the site was temporarily left unattended (e.g. washroom break), but the subject was in the same location and in the same position as when last observed, it was assumed for analytical purposes (as felids have the tendency to remain lying down for lengthy bouts of time) that no movement had taken place during the absence. If the subject was in a different location or position upon resuming observation, the missing minutes were equally divided between the two.

Activities were recorded as one of two categories of behavior: comfort behaviors and movement. Lying down, sitting, and being in the water (for the tigers only as there was a pool in their enclosure) fell under the former category and standing, walking, and running belonged to the latter. Comfort behaviors for summer weather conditions are those which decrease metabolic heat production and, in the case of being in the water and wetted by the water, have the ability to increase heat loss through convection (if the water is cooler than the surface temperature of the animal) and evaporation (once the animal leaves the water). It is important to note that the goals of comfort behavior would be opposite in winter conditions, where it would be desirable to increase metabolic heat production and to reduce heat loss. Standing was included under movement because it was a condition resulting from an active change in behaviors, either between two comfort behaviors, two other movement behaviors (walking or running), or between a comfort and a movement behavior. When the animal was lying or sitting on land, it was recorded whether the animal was in shade or sun. When no distinct shadow was seen at the time of the weather recording, it was noted whether the area where the animal was would be in shade or sun, given the time of day, if a distinct shadow 
had been observed. Lying down, sitting, movements, and behavior in the water that lasted over a minute in duration were all mutually exclusive categories. Occurrences of lying down or sitting that lasted less than a minute in duration were not recorded as a change in behavior. Movements that were under a minute shared that minute with the next comfort behavior, being considered as a transition between comfort positions, and were not tallied in the activity analysis.

The location of the animal during comfort behaviors was marked on a map of the enclosure. The maps were divided into landscape units, which are areas that differ in the resources they provide due to the characteristics of each unit (Brown 2008). For example, some landscape units were separated because they differ in the amount of solar radiation they each receive due to variation in slope, aspect and vegetation (Brown 2008).

The study took place during August and September 2009 with 18 observation days (9 days for each of the species), amounting to a total of 69 hours for the lions and 78.4 hours for the tigers. The males each had 5 observation days and the females each had 4.

All weather and behavior data recorded on site were transcribed to Microsoft Excel 2007. Each subject also had a comprehensive spreadsheet where collected data were organized in columns under the headings: Date, Time, Solar Radiation, Temperature, Humidity, Condition (whether the animal was in the sun, shade, or water), and Landscape Unit. The start time and finish time of each comfort behavior, represented under the condition and landscape unit categories, were each assigned to the solar radiation, temperature and humidity readings of the closest 15 minute weather recording interval and were inclusive of any readings in between. If the time of the comfort behavior was equal time from two weather readings, both readings were assigned. When, for example, three comfort behaviors occurred within the designated range of one weather reading time, indicated by a movement behavior interrupting them, the weather parameters would be tripled in frequency.

Wind levels did not reach more than $3 \mathrm{~m} / \mathrm{s}$ over the course of the study and this measurement only occurred for five reading times, with three out of five in one day. The majority of the wind speed readings were zero. Additionally, for 6 of the study days the anemometer was not available and so wind data were not taken during this time. Thus wind data were not included in the overall analysis. 
Though statistical analysis is a conventional means for data analysis in many papers, our study sought to discover patterns of individual condition and landscape unit use during the various weather conditions and these are better revealed through basic descriptive statistics. General relationships between the independent variables of temperature and solar radiation and the dependent variable of whether the subject was situated in the shade or sun were investigated through scatter plots generated in Excel. Solar radiation and temperature values that acted as a break point, where the sun and shade use above or below differed from the overall condition use, were identified. For the value to be considered a break point the following criteria had to be met: 1 . There had to be a gap in either the sun or shade column of at least 50 $\mathrm{W} / \mathrm{m}^{2}$ for solar radiation or $1^{\circ} \mathrm{C}$ for temperature, 2 . The greater of the two sets of data (sun and shade use) above and below the break point had to amount to more that $10 \%$ of the total number of data points for that graph and 3 . There had to be $10 \%$ or greater difference between at least one side (above or below) the break point and the overall condition use.

The scatter plots for the tigers excluded water use to allow more accurate comparison between the felid species. Humidity was not investigated in the scatter plot analysis either because only when combined with temperature into a temperature-humidity index (which is currently unknown for felids) will it better indicate the animal's use of resources than temperature alone. This is due to the fact that felines are only capable of very weakly sweating (through their footpads and nose only). Relying on panting (respiratory evaporation) for heat loss, relative humidity does not affect these animals as much as those who rely on sweating (Haley et al. 2008) and so felines are more sensitive to high temperatures than to high humidity (Bohmanova et al. 2007).

\section{Results}

\section{Weather}

All measured weather parameters are listed in Table 1 under the categories of daily lows, highs, and averages. Weather recordings revealed that there were different types of days during the study. First, all days were classified as a sunny day or a cloudy day which was determined by whether or not a distinct shadow was recorded, during each weather recording period, as present for the majority (over 50\%) of the observation day. Both of the female subjects were only observed on sunny days, while the male lion had 3 
sunny day and 2 cloudy day observation periods and the male tiger had 2 sunny day and 3 cloudy day observation periods. The weather data for the lions showed them both to have one day that was distinctly cooler than their other days so a cool day was an additional category for the lions. The remainder of the days for the lions and all of the days for the tigers were referred to as warm days, which includes a range of temperatures that could be considered to be warm to very warm to hot. The female tiger had the hottest observation days, followed closely by the lions' sunny warm days (for which the male's and female's days were very similar), and the male tiger had the coolest sunny warm days of observation.

Table 1 Measured microclimatic parameters

\begin{tabular}{|c|c|c|c|c|c|c|c|c|c|}
\hline $\begin{array}{c}\text { Date } \\
(2009)\end{array}$ & $\begin{array}{c}\text { Ambient } \\
\text { Temperature } \\
\text { High }(\square \mathrm{C})\end{array}$ & $\begin{array}{c}\text { Ambient } \\
\text { Temperature } \\
\text { Low }(\square \mathrm{C})\end{array}$ & $\begin{array}{c}\text { Ambient } \\
\text { Temperature } \\
\text { Average } \\
(\square \mathrm{C})\end{array}$ & $\begin{array}{l}\text { Relative } \\
\text { Humidity } \\
\text { High }(\%)\end{array}$ & $\begin{array}{l}\text { Relative } \\
\text { Humidity } \\
\text { Low }(\%)\end{array}$ & $\begin{array}{c}\text { Relative } \\
\text { Humidity } \\
\text { Average } \\
(\%)\end{array}$ & $\begin{array}{c}\text { Solar } \\
\text { Radiation } \\
\text { High } \\
\left(\mathrm{W} / \mathrm{m}^{2}\right)\end{array}$ & $\begin{array}{c}\text { Solar } \\
\text { Radiation } \\
\text { Low } \\
\left(\mathrm{W} / \mathrm{m}^{2}\right)\end{array}$ & $\begin{array}{c}\text { Solar } \\
\text { Radiation } \\
\text { Average } \\
\left(\mathrm{W} / \mathrm{m}^{2}\right)\end{array}$ \\
\hline Male Lion & & & & & & & & & \\
\hline August 13 & 31.4 & 26.1 & 29.3 & 58.1 & 46.0 & 51.5 & 1013.2 & 73.1 & 700.7 \\
\hline August 23 & 30.5 & 21.1 & 25.2 & 68.2 & 44.7 & 58.6 & 1110.6 & 20.2 & 438.7 \\
\hline September 8 & 27.8 & 24.1 & 25.7 & 65.6 & 52.0 & 56.8 & 972.8 & 258.9 & 734.4 \\
\hline September 14 & 25.6 & 22.1 & 24.2 & 55.1 & 46.9 & 50.7 & 805.3 & 87.4 & 471.6 \\
\hline September 26 & 20.9 & 15.7 & 17.6 & 82.8 & 51.9 & 66.0 & 528.6 & 4.1 & 184.2 \\
\hline \multicolumn{10}{|l|}{ Female Lion } \\
\hline August 14 & 31.0 & 27.4 & 29.6 & 60.7 & 47.7 & 53.9 & 906.9 & 109.5 & 678.1 \\
\hline September 6 & 26.2 & 20.1 & 23.8 & 60.1 & 43.2 & 50.2 & 1033.8 & 68.9 & 722.0 \\
\hline September 13 & 28.4 & 22.1 & 25.4 & 66.6 & 44.3 & 52.4 & 811.3 & 104.6 & 483.0 \\
\hline September 25 & 19.9 & 13.7 & 16.6 & 61.3 & 41.1 & 49.9 & 788.9 & 134.0 & 608.2 \\
\hline \multicolumn{10}{|l|}{ Male Tiger } \\
\hline August 10 & 30.2 & 23.1 & 25.8 & 89.6 & 63.7 & 77.3 & 1125.2 & 44.4 & 339.3 \\
\hline August 26 & 24.8 & 20.3 & 22.5 & 78.7 & 44.6 & 55.2 & 1097.6 & 60.7 & 558.3 \\
\hline September 9 & 25.3 & 22.0 & 24.1 & 64.0 & 49.2 & 55.7 & 985.4 & 272.2 & 736.2 \\
\hline September 11 & 22.0 & 18.8 & 20.6 & 66.2 & 39.0 & 50.3 & 636.4 & 66.9 & 383.1 \\
\hline September 27 & 21.2 & 17.5 & 19.3 & 85.9 & 66.0 & 74.9 & 784.1 & 8.3 & 246.9 \\
\hline \multicolumn{10}{|l|}{ Female Tiger } \\
\hline August 11 & 28.2 & 23.4 & 25.0 & 78.0 & 54.6 & 67.9 & 1038.7 & 86.4 & 333.2 \\
\hline August 15 & 29.4 & 26.3 & 28.2 & 65.9 & 48.3 & 57.3 & 874.1 & 117.0 & 627.9 \\
\hline August 16 & 31.8 & 26.1 & 29.4 & 70.0 & 46.8 & 55.4 & 858.5 & 64.8 & 594.9 \\
\hline August 20 & 29.5 & 25.5 & 27.8 & 76.8 & 62.0 & 67.8 & 928.5 & 3.1 & 460.1 \\
\hline
\end{tabular}

Activity

The lions and tigers spent the vast majority of their time performing comfort behaviors, defined in this study as lying, sitting, or being in the water. In both species, sitting accounted for only $1 \%$ or less of each individual's total comfort time and the male and female tiger were in the water $3 \%$ and $4 \%$ of their respective total comfort time, with a low of 6 minutes in one day to a high of 30 minutes another day, so most comfort behavior was lying on land. The tigers spent a greater portion of their day moving around the 
enclosure than did the lions. The tigers spent between $65 \%$ and $86 \%$ of their time performing comfort behaviors while the lions spent between $93 \%$ and $98 \%$ (see Table 2 for individual daily behavior distribution). The longest amount of time that the subjects were observed to stay in one location ranged from just over 2 hours to more than 4 hours; the tigers exhibited the longest times. Both of the lions and the female tiger were all more active on their coolest days of observation, while the male tiger was the least active on his two hottest days (refer to days listed in Tables 1 and 2). The male lion was also more active on his cloudy days than his sunny days, a pattern that was not displayed by the male tiger. The male tiger was the most active on a sunny day, not the coolest of his days, though on this day he used sun the least amount (refer to Table 3).

Table 2 Daily minutes and percent of time spent performing comfort behaviors and movement. Comfort behavior includes water use for the tigers

\begin{tabular}{|l|c|c|c|c|c|}
\hline \multicolumn{1}{|c|}{$\begin{array}{c}\text { Date } \\
\text { (2009) }\end{array}$} & \multicolumn{2}{c|}{ Comfort Behavior } & \multicolumn{2}{c|}{ Movement Behavior } & $\begin{array}{c}\text { Total } \\
\text { Observed } \\
\text { Time }\end{array}$ \\
\cline { 2 - 5 } & Minutes & $\%$ & Minutes & $\%$ & Minutes \\
\hline Male Lion & 484.0 & 98 & 11.0 & 2 & 495.0 \\
August 13 - Sunny & 523.5 & 96 & 24.5 & 4 & 548.0 \\
August 23 - Cloudy & 413.0 & 98 & 8.0 & 2 & 421.0 \\
September 8 - Sunny & 388.0 & 97 & 11.0 & 3 & 399.0 \\
September 14 - Sunny & 377.0 & 93 & 30.0 & 7 & 407.0 \\
September 26 - Cloudy & & & & & \\
Female Lion & & & & & \\
August 14 - Sunny & 495.0 & 98 & 12.0 & 2 & 507.0 \\
September 6 - Sunny & 487.5 & 98 & 11.5 & 2 & 499.0 \\
September 13 - Sunny & 450.5 & 97 & 14.5 & 3 & 464.0 \\
September 25 - Sunny & 383.5 & 96 & 17.0 & 4 & 400.5 \\
& & & & & \\
Male Tiger & & & & & \\
August 10 - Cloudy & 433.0 & 78 & 121.0 & 22 & 554.0 \\
August 26 - Sunny & 357.0 & 65 & 193.0 & 35 & 550.0 \\
September 9 - Sunny & 367.5 & 78 & 101.5 & 22 & 469.0 \\
September 11 - Cloudy & 346.5 & 74 & 124.5 & 26 & 471.0 \\
September 27 - Cloudy & 349.0 & 75 & 118.0 & 25 & 467.0 \\
Female Tiger & & & & & \\
August 11 - Sunny & 366.5 & 67 & 180.5 & 33 & 547.0 \\
August 15 - Sunny & 423.5 & 79 & 113.5 & 21 & 537.0 \\
August 16 - Sunny & 457.5 & 81 & 107.5 & 19 & 565.0 \\
August 20 - Sunny & 468.0 & 86 & 76.0 & 14 & 544.0 \\
\hline
\end{tabular}




\section{Landscape Units}

In terms of landscape units, characterized by the resources that they provide, all individuals differed in their use of the available shade sources: tree(s), gunite wall (lions only), den (tigers only), housing (tigers only), and other. The 'other' category includes shade by a large boulder and by topography for the lions and shade under a tree but either beside a large rock or between a large rock and a short gunite wall for the tigers. The male lion almost entirely used trees as his shade source, with the exception of $6 \%$ (total of 63 minutes) of shade time on his sunny warm days when he used shade provided from gunite walls, 46 minutes of which were on his hottest day (August 13). The female lion mainly used shade provided by the gunite walls, with $94 \%$ use on sunny warm days and $78 \%$ on her sunny cool day. Trees comprised $2 \%$ and $18 \%$ of the female lion's warm days and cool day, respectively, and the remainder was under the 'other' category. The male tiger's main shade was from the den, with $89 \%$ use on sunny days and $96 \%$ use on cloudy days, where female tiger relied more on the shade from the housing along the southern edge of the enclosure (49\%). The rest of the female tiger's shade use was divided similarly between the den and trees at $27 \%$ and $25 \%$, respectively. The male tiger used trees for shade $6 \%$ on his sunny days and 3\% on the cloudy days. On her coolest day (August 11), the female tiger used neither the den nor shade provided by the housing, all of which provide the densest amount of shade.

Considering substrate, the lions had grass and several basking rocks (gunite and real), while the tigers had grass, the mulch in the den, and compacted earth along the regularly walked area in front of their housing. On warm days, the lioness used the real rock $12 \%$ of the total observed comfort time and the gunite basking rock $5 \%$ of the time. On her cool day, the real rock was used 3\% of the time and the gunite was not used as a substrate. On both day categories, the real rock was only used while in the sun and the gunite when it was in the shade. The male lion did not make use of the basking rocks.

The tigers both used their water pool every day. Daily use ranged from 2\% (equivalent to 6 minutes) on his coolest day to $6 \%$ (equivalent to 27 minutes) on his hottest day, August 10, for the male tiger and $1 \%$ (equivalent to 6.5 minutes) to $8 \%$ (equivalent to 30 minutes) for the female tiger. The female tiger spent the most time in the water on her coolest day (August 11), which was also the day that she spent the most time in the sun and was the most active (Tables 2 and 3). The male's August 10 had almost double the minutes of water use than the next most used water day (August 26 with 14 minutes). Humidity 
differed greatly between these two days with August 10 having an average relative humidity $22 \%$ greater than August 26 (Table 1). The other difference between the two days is that August 10 was cloudy while the other was sunny. The male and female used the water pool differently: the male spent the majority of his time playing with a toy in the water, while the female exclusively spent her time lying partially submerged in the water.

Table 3 Subject daily use of sun and shade for the total observed time

\begin{tabular}{|c|c|c|c|}
\hline Date (2009) & Type of Day & Sun & Shade \\
\hline \multicolumn{4}{|c|}{ Male Lion } \\
\hline August 13 & Sunny Warm & $9 \%$ & $91 \%$ \\
\hline August 23 & Cloudy Warm & $27 \%$ & $73 \%$ \\
\hline September 8 & Sunny Warm & $17 \%$ & $83 \%$ \\
\hline September 14 & Sunny Warm & $39 \%$ & $61 \%$ \\
\hline September 26 & Cloudy Cool & $100 \%$ & $0 \%$ \\
\hline \multicolumn{2}{|c|}{ Total Sunny Warm Days } & $20 \%$ & $80 \%$ \\
\hline \multicolumn{4}{|c|}{ Female Lion } \\
\hline August 14 & Sunny Warm & $23 \%$ & $77 \%$ \\
\hline September 6 & Sunny Warm & $41 \%$ & $59 \%$ \\
\hline September 13 & Sunny Warm & $27 \%$ & $73 \%$ \\
\hline September 25 & Sunny Cool & $56 \%$ & $44 \%$ \\
\hline \multicolumn{2}{|c|}{ Total Sunny Warm Days } & $30 \%$ & $70 \%$ \\
\hline \multicolumn{4}{|c|}{ Male Tiger } \\
\hline August 10 & Cloudy Warm & $45 \%$ & $55 \%$ \\
\hline August 26 & Sunny Warm & $10 \%$ & $90 \%$ \\
\hline September 9 & Sunny Warm & $23 \%$ & $77 \%$ \\
\hline September 11 & Cloudy Warm & $80 \%$ & $20 \%$ \\
\hline September 27 & Cloudy Warm & $31 \%$ & $69 \%$ \\
\hline \multicolumn{2}{|c|}{ Total Sunny Warm Days } & $16 \%$ & $84 \%$ \\
\hline \multicolumn{2}{|c|}{ Total Cloudy Warm Days } & $51 \%$ & $49 \%$ \\
\hline \multicolumn{4}{|c|}{ Female Tiger } \\
\hline August 11 & Sunny Warm & $40 \%$ & $60 \%$ \\
\hline August 15 & Sunny Warm & $1 \%$ & $99 \%$ \\
\hline August 16 & Sunny Warm & $1 \%$ & $99 \%$ \\
\hline August 20 & Sunny Warm & $3 \%$ & $97 \%$ \\
\hline \multicolumn{2}{|c|}{ Total Sunny Warm Days } & $9.5 \%$ & $90.5 \%$ \\
\hline
\end{tabular}

\section{Condition Use (Sun and Shade)}

Table 3 illustrates each subject's daily use of sun and shade for total observed comfort time and lists the type of day each day was classified as. On sunny warm days all of the subjects used shade more 
than sun locations. The lions showed a similar pattern use of sun and shade for their total sunny warm days, though the female used sun $10 \%$ more than the male. The male tiger had similar condition use to the male lion for total sunny warm days, with $16 \%$ and $20 \%$ sun use, respectively, though it should be noted that the male tiger's days were cooler than the male lion's days. Of the subjects, the female tiger used shade the most; she was also the one with the highest air temperatures during observation (Table 1). On the female lion's cool day, her condition (sun and shade) use was near equal, while the male lion spent $100 \%$ of his time in the sun. A difference between these two days was that the male's was cloudy and the female's was sunny.

August 23 was the only cloudy warm day for the male lion and there was only a $7 \%$ difference in the condition percents from the sunny warm days' total use. On the cloudy day that $7 \%$ difference is in favor of being in the sun more. The male and female lion each had a day where they used sun and shade in the same proportions: August 23 and September 13, respectively, though the male's was cloudy and the female's was sunny. These two days had essentially the same average temperature as well $\left(25.2^{\circ} \mathrm{C}\right.$ and $25.4^{\circ} \mathrm{C}$ ). The male lion was more active on this day than his sunny days (Table 2 ).

The male tiger used sun more often on his cloudy days than sunny days. September 11 presented a distinctly different use than the other cloudy days, where $80 \%$ of the tiger's time was spent in the sun versus $31 \%$ and $45 \%$ on the other cloudy days. Similarly, the female tiger had one day that showed a distinctly different use from her other days: August 11 had a 40\% sun use whereas the other days had an average of $2 \%$ sun use. On this day, the female tiger's condition use was similar to the male tiger's use on August 10, with $45 \%$ sun use. August 10 and 11 had a similar average temperature for the day, $25.8^{\circ} \mathrm{C}$ and $25^{\circ} \mathrm{C}$, respectively. The female was more active on her day than the male and the female's day was a sunny day versus the male's cloudy day.

\section{Scatter Plots}

Information from the scatter plots is displayed in Tables 4 through to 7 and includes the total sun and shade use for each type of day and solar radiation and temperature break points that resulted in a different break down of condition use. There were discrepancies between the overall condition uses for the scatter plot data (Tables 4 to 7) and those from the total observed time (Table 3) due to differences in the 
total number of data points, as the scatter plot data were based on the frequency of weather measurements versus total observed time in minutes. The lions both had less than a $5 \%$ difference between their scatter plot condition use and that of their total observed time and there was only a $1.5 \%$ difference for the female tiger. The scatter plot data for the male tiger though indicated $16.5 \%$ less shade use on sunny days and $10 \%$ less shade use on cloudy days than seen in the total observed time data.

Table 4 Scatter plot data showing sun and shade use and break points for the male lion

\begin{tabular}{|c|c|c|c|c|}
\hline \multicolumn{2}{|c|}{ Male Lion } & & & \\
\hline \multicolumn{2}{|c|}{$<$} & \multirow{2}{*}{ Break Point } & \multicolumn{2}{|c|}{$>$} \\
\hline Sun & Shade & & Sun & Shade \\
\hline \multicolumn{2}{|c|}{ Sunny Warm Days } & \multicolumn{3}{|c|}{ Overall Use: $23 \%$ Sun; $77 \%$ Shade } \\
\hline $33 \%$ & $67 \%$ & $300 \mathrm{~W} / \mathrm{m}^{2}$ & $20 \%$ & $80 \%$ \\
\hline $36 \%$ & $64 \%$ & $350 \mathrm{~W} / \mathrm{m}^{2}$ & $20 \%$ & $80 \%$ \\
\hline $33 \%$ & $67 \%$ & $550 \mathrm{~W} / \mathrm{m}^{2}$ & $19 \%$ & $81 \%$ \\
\hline $33 \%$ & $67 \%$ & $27^{\circ} \mathrm{C}$ & $9 \%$ & $91 \%$ \\
\hline \multicolumn{2}{|c|}{ Cloudy Warm Day } & \multicolumn{3}{|c|}{ Overall Use: $23 \%$ Sun; $77 \%$ Shade } \\
\hline $0 \%$ & $100 \%$ & $150 \mathrm{~W} / \mathrm{m}^{2}$ & $29 \%$ & $71 \%$ \\
\hline $28 \%$ & $72 \%$ & $500 \mathrm{~W} / \mathrm{m}^{2}$ & $10 \%$ & $90 \%$ \\
\hline $30 \%$ & $70 \%$ & $550 \mathrm{~W} / \mathrm{m}^{2}$ & $0 \%$ & $100 \%$ \\
\hline $29 \%$ & $71 \%$ & $26^{\circ} \mathrm{C}$ & $9 \%$ & $91 \%$ \\
\hline $28 \%$ & $72 \%$ & $27^{\circ} \mathrm{C}$ & $0 \%$ & $100 \%$ \\
\hline \multicolumn{2}{|c|}{ Cloudy Cool Day $\left(<21^{\circ} \mathrm{C}\right)$} & \multicolumn{3}{|c|}{ Overall Use: $100 \%$ Sun; 0\% Shade } \\
\hline
\end{tabular}

Table 5 Scatter plot data showing sun and shade use and break points for the female lion

\begin{tabular}{|c|c|c|c|c|}
\hline \multicolumn{2}{|c|}{ Female Lion } & \multicolumn{2}{|c|}{$>$} \\
\hline \multicolumn{2}{|c|}{ Break Point } & \multicolumn{2}{|c|}{ Sun } & Shade \\
\cline { 1 - 1 } Sun & Shade & & Sun & Overall Use: $29 \%$ Sun; $71 \%$ Shade \\
\hline \multicolumn{2}{|c|}{ Sunny Warm Days } & & Overall Use: $51 \%$ Sun; $49 \%$ Shade \\
\hline Sunny Cool Day $\left(<20^{\circ} \mathrm{C}\right)$ & & $400 \mathrm{~W} / \mathrm{m}^{2}$ & $56 \%$ & $44 \%$ \\
\hline $36 \%$ & $64 \%$ & &
\end{tabular}


Table 6 Scatter plot data showing sun and shade use and break points for the male tiger

\begin{tabular}{|c|c|c|c|c|}
\hline \multicolumn{2}{|c|}{ Male Tiger } & & & \\
\hline \multicolumn{2}{|c|}{$\leq$} & \multirow{2}{*}{ Break Point } & \multicolumn{2}{|c|}{$>$} \\
\hline Sun & Shade & & Sun & Shade \\
\hline \multicolumn{2}{|c|}{ Sunny Warm Days } & \multicolumn{3}{|c|}{ Overall Use: $32.5 \%$ Sun; $67.5 \%$ Shade } \\
\hline $47 \%$ & $53 \%$ & $400 \mathrm{~W} / \mathrm{m}^{2}$ & $29 \%$ & $71 \%$ \\
\hline $62.5 \%$ & $37.5 \%$ & $450 \mathrm{~W} / \mathrm{m}^{2}$ & $20 \%$ & $80 \%$ \\
\hline $62 \%$ & $38 \%$ & $500 \mathrm{~W} / \mathrm{m}^{2}$ & $19 \%$ & $81 \%$ \\
\hline $59 \%$ & $41 \%$ & $600 \mathrm{~W} / \mathrm{m}^{2}$ & $15 \%$ & $85 \%$ \\
\hline $50 \%$ & $50 \%$ & $750 \mathrm{~W} / \mathrm{m}^{2}$ & $15 \%$ & $85 \%$ \\
\hline $39 \%$ & $61 \%$ & $850 \mathrm{~W} / \mathrm{m}^{2}$ & $19 \%$ & $81 \%$ \\
\hline \multicolumn{2}{|c|}{ Cloudy Warm Days } & \multicolumn{3}{|c|}{ Overall Use: $61 \%$ Sun; $39 \%$ Shade } \\
\hline $67 \%$ & $33 \%$ & $22{ }^{\circ} \mathrm{C}$ & $51 \%$ & $49 \%$ \\
\hline
\end{tabular}

Table 7 Scatter plot data showing sun and shade use and break points for the female tiger

\begin{tabular}{|c|c|c|c|c|}
\hline \multicolumn{2}{|c|}{ Female Tiger } & \multicolumn{2}{|c|}{\multirow{2}{*}{ Break Point }} & \multicolumn{2}{|c|}{$\geq$} \\
\cline { 5 - 6 } \cline { 5 - 5 } Sun & Shade & & Sun & Shade \\
\hline \multicolumn{2}{|c|}{ Sunny Warm Days } & \multicolumn{2}{|c|}{ Overall Use: $11 \%$ Sun; 89\% Shade } \\
\hline $33 \%$ & $67 \%$ & $250 \mathrm{~W} / \mathrm{m}^{2}$ & $3 \%$ & $97 \%$ \\
\hline $26 \%$ & $74 \%$ & $400 \mathrm{~W} / \mathrm{m}^{2}$ & $1 \%$ & $99 \%$ \\
\hline $23 \%$ & $77 \%$ & $550 \mathrm{~W} / \mathrm{m}^{2}$ & $0 \%$ & $100 \%$ \\
\hline $22 \%$ & $78 \%$ & $28^{\circ} \mathrm{C}$ & $2 \%$ & $98 \%$ \\
\hline $15 \%$ & $85 \%$ & $29^{\circ} \mathrm{C}$ & $0 \%$ & $100 \%$ \\
\hline
\end{tabular}

\section{Break Points}

The sunny warm days and the cloudy warm day for the male lion had a same break point for both solar radiation and temperature: $550 \mathrm{~W} / \mathrm{m}^{2}$ and $27^{\circ} \mathrm{C}$, however, above and below (to a lesser degree) this break point the subject used shade more on the cloudy warm day than the sunny warm days (see Table 4). On his cloudy warm day (August 23), these same values led to $100 \%$ use of shade above the break point. He was also more active (4\%) on August 23 than his sunny warm days (2.3\% average movement). The 
female tiger also had $100 \%$ use of shade above her break point of $550 \mathrm{~W} / \mathrm{m}^{2}$, though this was on sunny warm days, as well as above $29^{\circ} \mathrm{C}$ (Table 7). For the male tiger, below three of his solar radiation break points on his sunny warm days $\left(450 \mathrm{~W} / \mathrm{m}^{2}, 500 \mathrm{~W} / \mathrm{m}^{2}\right.$ and $\left.600 \mathrm{~W} / \mathrm{m}^{2}\right)$ there was an opposite pattern of use from the overall condition use, where sun was used more than shade (Table 6).

\section{Discussion}

As previously mentioned, the energy budget of an animal is the key to understanding its thermal comfort, which was explored in this study primarily in terms of sun and shade use. Of the variables of an animal's energy budget $\left(M+R_{a b s}=R_{e m i t}+C+E+K+X\right)$, some are much more effective means of heat transfer for lions and tigers than others. Evaporative heat loss is largely limited to panting in felids, though the process of sweating can by mimicked by wetting the pelage and skin such as when the tigers emerged from their water pool. Convective heat loss is minimized by the high insulation level of their coats. Determining the study subjects' activities, along with corresponding locations of where they spent time, and the microclimatic conditions under which these occurred throughout the day provided insight into how the animals were behaviorally adjusting their heat balance. The felids in our study employed various methods for staying cooler on hot days: decreasing their metabolism (limiting activity), reducing the amount of solar and terrestrial radiation received (lying in the shade and/or near cool surfaces), increasing their evaporative heat loss artificially by entering water, and/or lying on cool surfaces to increase their conductive heat loss. Given that our subjects spent the majority of their day lying down, conduction between the animal and the given substrate plays a key role in their energy budget. The amount of heat loss or gain between the animal and substrate will be affected by the substrate composition because different materials vary in their thermal admittance, "a surface thermal property that governs the ease with which it will take up or release heat" (Oke 1987). As an example, the female lion only chose to use the gunite rock when it was shaded and the natural rock for basking when it was in the sun. When both of these features (being of comparable size) are exposed to direct beam solar radiation in the same weather conditions, the gunite rock reaches a higher temperature than the natural rock (Young 2009, personal communication). With a higher surface temperature, the gunite basking rock may have been uncomfortably hot when in the sun during the weather conditions of this study. 
Separating days into sunny or cloudy days was indicative of the solar radiation conditions of that day, where cloudy days had less direct beam solar radiation than sunny days. Having mostly diffuse solar radiation, in which the amounts are indiscriminate between sunny or shaded areas, one would hypothesize that the animals would be less discriminate between their sun and shade use. Our results supported this notion: August 23 (cloudy) and September 8 (sunny) had similar temperatures but on the cloudy day the male lion used the sun 10\% more (in addition to being over twice as active) and the male tiger used sun more often on each cloudy day than his two sunny days.

The subjects were chosen to compare male and female within the same species and between species, in particular ones originating from native habitats with climates differing from one another and from that of their zoo location. Though animals have the capability of acclimatizing to different climates, one might have expected to find differences between the African lion and Amur tiger given pelage differences. Generally, each subject displayed quite a bit of variation in the use of sun and shade, even between similarly categorized days. Considering the total average temperature of each subject's warm sunny days, the day category that was present for all of the subjects, the male and female lion had the same ambient air temperatures $\left(26.4^{\circ} \mathrm{C}\right.$ and $26.3^{\circ} \mathrm{C}$, respectively), while the male tiger had the lowest $\left(23.3^{\circ} \mathrm{C}\right)$ and the female tiger the highest $\left(27.6^{\circ} \mathrm{C}\right)$. Due to opposing weather conditions, direct intraspecies comparisons for the tigers were not possible. For the lions, their sunny warm days were similar in temperature and the animals expressed the same activity levels. The female used sun $10 \%$ more than the male, however, she also used more dense shade (gunite walls) than the male (trees) which may account for the difference.

Given the differences in air temperature for each subject's set of observation days, there seems to be species-specific differences between the lions and the tigers. Condition use on these days revealed that although the male tiger had cooler days than the lions, he still used sun less than the lions and, though the female tiger's days were less than a degree and a half hotter than the lions, she used sun much less than the lions, particularly when August 11 was not taken into account (refer to Table 3). These results show that the tigers were more limiting with their solar radiation input compared to the lions. However, solely looking at this condition (sun and shade) use may be misleading in deciding if there are differences between the species, in terms of summer thermal comfort. Since the tigers were more active than the lions 
(refer to Table 2), they would have had a higher metabolic heat input and so the tigers' more frequent use of shade may in fact be compensation for this difference in metabolic heat gain and not truly a difference in response to temperature alone.

There was another observed behavior that differed between the lions and tigers: panting. Though it was not a specific focus of the study, whenever panting was observed, it was noted; the lions were not seen to express this method of excess heat release (respiratory evaporation) but the tigers both were (the male showed this behavior more than the female), indicating that there were circumstances leading to the tigers experiencing heat stress. The day that the male tiger spent the most time in the sun (September 11) at $80 \%$ was also the day that he was observed to pant the most. This day was similar in temperature and solar radiation to September 27 , which had $31 \%$ sun use but differed in humidity, where September 11 had a $66 \%$ relative humidity and September 27 had $86 \%$. Panting would be more effective for heat release in lower humidity so this may be why the subject could 'afford' to be in the sun more on the lower humidity day.

The difference in the average temperature between the male tiger's sunny and cloudy days was slight at $1.4^{\circ} \mathrm{C}$, yet his use of sun and shade between these two categories of days differed by $35 \%$. This situation provides support to the theoretical knowledge that solar radiation and temperature have a combined effect on an animal's thermal comfort. The female tiger's one day that is significantly different in sun and shade use from the others (August 11) is a day where the majority of distinct shadow versus indistinct (to classify it as a sunny day) was $56 \%$ versus $44 \%$. It is possible that had more frequent weather recordings been made that this day would have classified as a cloudy day following the selection criteria. Another one of the female tiger's days also classified as a sunny day (August 20) with just a slight majority of distinct shadows recorded at 53\%. However, this day showed similar sun and shade use patterns as the other two days. The only other subject's day that had similar distinct and indistinct shadow results was August 10 for the male tiger (46\% sun and so was a cloudy day). None of the other observation days had the potential for such a discrepancy, having $60 \%$ to $100 \%$ majority.

The data set used to create the scatter plots revealed discrepancies between the condition use percentages for them (Tables 4 to 7) and for those resulting from the total observed time (Table 3), particularly for the male tiger. The reason why only one subject out of the four showed a large difference 
has not been identifiable. This finding does highlight how interval sampling, in this case every 15 minutes, can produce misleading results compared to continuous sampling. The scatter plots were a valuable method of analysis though as break points identified specific solar radiation and temperature conditions effect on the subject's use of sun and shade.

There were three main limitations to the current study due to the time constraints of the project and because it was an exploratory study. Firstly, the sample size was limited to four individuals. Secondly, due the equipment use scheduling and the unpredictability of which subject was going to be available for observation on a given day, it was not possible to balance the numbers of each type of day (sunny/cloudy; warm/cool) between the subjects through planning according to the weather forecast. Thirdly, observations were limited to summer months.

This study provides a foundation for several avenues of future research that will expand the current knowledge base found in the literature. The next steps would be to conduct similar studies, with more days under each day category, on other individual animals for comparison and to compare different age groups. As well, the animals will use their enclosure differently in the winter and will have a different heat budget. Given that North American zoos face seasonal extremes, enclosures need to be designed to maximize comfort in both summer and winter seasons. A study, following the methodology of the current study, in the winter season would be valuable.

Determining how other design features are used, with regard to the thermal comfort of lions and tigers, would be incredibly beneficial as well. Additionally, the thermal properties of the elements within zoo enclosures (e.g. gunite walls and different substrates) and how they respond in varying weather conditions require more in depth examination to further address how they influence the microclimate adjacent to them, and thus the thermal comfort of the animals using those resources. Furthermore, this kind of study can be and should be applied to other species.

The complexity and difficulty in understanding and predicting an animal's thermal comfort was illustrated by this study, which further stresses the importance of this area of research. Though there is much more knowledge to be gained on this topic, in the meantime, it is important for zoo designers to consider carefully the microclimatic needs of an animal with respect to its energy budget through all seasons. Key points of this study are that 1) shade is an essential resource in the summer months; 2) it is of 
great importance to maximize the thermal range of choice that a zoo animal has within its enclosure

throughout the day; and 3) a water pool is a valuable resource for the thermal comfort of tigers.

\section{Acknowledgements}

We would like to extend our sincerest gratitude to Eric Morris, Toronto Zoo Facilities and Services

Director, for allowing this research to be conducted, to Dr. Terry Gillespie, Dr. Andrew Gordon, and Dr.

Naresh Thevathasan from the University of Guelph for lending their meteorological instruments, and to Dr.

Steve Miller from the University of Guelph for the use of his infrared camera. As well, the overall comprehension and detail of this paper has been improved due to input from our anonymous reviewers to whom we give our thanks. 


\section{References}

Bohmanova J, Misztal I, Cole JB (2007) Temperature-Humidity Indices as Indicators of Milk Production Losses due to Heat Stress. J Dairy Sci 90 (4):1947-1956

Brown R (2008) Landscape assessment for planning and design: Seeing the landscape again for the first time. VDM Verlag Dr. MÜller, SaarbrÜcken, Germany

Brown RD, Gillespie TJ (1995) Microclimatic landscape design: Creating thermal comfort and energy efficiency. John Wiley \& Sons, New York

Campbell GS, Norman JM (1998) An introduction to environmental biophysics, 2nd edn. Springer-Verlag, New York

Haley C, Dewey CE, Widowski T, Poljak Z, Friendship R (2008) Factors associated with in-transit losses of market hogs in Ontario in 2001. Can J Vet Res 72:377-384

Hansen PJ (2009) Effects of heat stress on mammalian reproduction. Philos Trans R Soc B 364:3341-3350

Hediger H (1950) Wild Animals in Captivity. Butterworths Scientific Publications, London

Hosey G, Melfi V, Pankhurst S (2009) Zoo animals: Behavior, management, and welfare. Oxford University Press, New York

Johnson HD (1997) Aspects of animal biometeorology in the past and future. Int J Biometeorol 40:16-18

Kirkwood JK (1999) Accommodation for wild animals in captivity: How do we know when we've got it right? In: Plowman AB, Stevens PMC (eds) Conservation centres for the new millennium: Proceedings of the 5th International Symposium on Zoo Design. Whitley Wildlife Conservation Trust, Paignton, Devon, UK, pp 51-62

LangmanVA, Rowe M, Forthman D, Whitton B, Langman N, Roberts T, Huston K, Boling C, Maloney D (1996) Thermal assessment of zoological exhibits 1: Sea lion enclosure at the Audubon Zoo. Zoo Biol $15: 403-411$

Litchfield C, Dorrian J, Davis J, Lushington K, Dawson D (2011) Lessons in Primate Heat Tolerance: A Commentary Based on the "Human Zoo" Experience. J Appl Anim Welf Sci 14:162-169

Margulis SW, Hoyos C, Anderson M (2003) Effect of felid activity on zoo visitor interest. Zoo Biol 22:587-599

Martin P, Bateson P (1993) Measuring behavior: An introductory guide, 2nd edn. Cambridge University Press, Cambridge

Morgan KN, Tromborg CT (2007) Sources of stress in captivity. Appl Anim Behav Sci 102:262-302

Oke TR (1987). Boundary layer climates, second edition. Methuen, London

Webster J (1994) Animal welfare: A cool eye towards Eden. Blackwell Science, Oxford

Widowski T (1998) Beat the Heat, A Guide to Hot Weather and Shade for Ontario Cattle Producers. The Colonel KL Campbell Centre for the Study of Animal Welfare, University of Guelph 
Young RJ (2003) Environmental enrichment for captive animals: UFAW Animal Welfare Series. Blackwell Publishing Company, Oxford, UK 